\title{
LXXV.-CONTRIBUTIONS FROM THE LABORATORIES OF THE HERIOT WATT COLLEGE, EDINBURGH.
}

\section{Acetylcarbinol.}

\author{
By W. H. Perkin, Jun., Ph.D., F.R.S.
}

AL'THOUGH several members of the series of ketone alcohols have been isolated and described, it is surprising, in view of the great interest attaching to these compounds, that the first member of the series, acetylcarbinol (acetol, acetone alcohol), $\mathrm{CH}_{3} \cdot \mathrm{CO}^{\cdot} \mathrm{CH}_{2} \cdot \mathrm{OH}$, has hitherto been obtained only in aqueous solution.

In this form it has been obtained by the following reactions:-

1. When a-chlorallyl alcohol, $\mathrm{CH}_{2} \cdot \mathrm{COl} \cdot \mathrm{CH}_{2} \cdot \mathrm{OH}$, is dissolved in concentrated sulphuric acid, and the product distilled in a current of steam, a dilute aqueous solution of acetylcarbinol passes over (Henry, $B l ., 39,526)$.

2. When caustic potash is added to fused cane sugar or grape sugar in a retort, an aqueous distillate is obtained which contains acetylcarbinol (Emmerling and Lodges, Ber., 16, 837).

3. When monobromacetone, $\mathrm{CH}_{2} \mathrm{Br} \cdot \mathrm{CO}^{\cdot} \mathrm{CH}_{3}$, is treated in aqueous solution with silver oxide, acetylcarbinol is formed. By the action of potassium carbonate on monobromacetone, Emmerling and Wagner (Annalen, 204, 40) obtained a sweet substance, which was very soluble in water, reduced Fehling's solution, and which these authors supposed to be acetylcarbinol.

I have carefully repeated this latter experiment under very varied conditions, but, although I obtained a substance closely resembling the product described by Emmerling and Wagner, it was, certainly, not acetylcarbinol, as it did not distil without decomposition, and, on 
analysis, numbers were obtained which differed widely from those required by the formula $\mathrm{CH}_{3} \cdot \mathrm{CO} \cdot \mathrm{CH}_{2} \cdot \mathrm{OH}$.

Although acetylcarbinol itself has not been isolated, derivatives of this alcohol are well known; thus alkyl ethers of acetylcarbinol have been prepared from the corresponding propargyl compounds (Henry, $J ., 1881$, 506) by hydration by means of mercuric bromide, thus :-

$$
\mathrm{CH}: \mathrm{C}^{-} \mathrm{CH}_{2} \cdot \mathrm{OC}_{2} \mathrm{H}_{5}+\mathrm{H}_{2} \mathrm{O}=\mathrm{CH}_{3} \cdot \mathrm{CO} \cdot \mathrm{CH}_{2} \cdot \mathrm{OC}_{2} \mathrm{H}_{5} ;
$$

and acetylcarbinyl acetate, $\mathrm{CH}_{3} \cdot \mathrm{CO} \cdot \mathrm{CH}_{2} \cdot \mathrm{O} \cdot \mathrm{C}_{2} \mathrm{H}_{3} \mathrm{O}$, was long ago prepared by the same chemist (Ber., 5, 966), and by Zincke and Breuer (Ber., 13,638), by digesting monochloracetone with potassium acetate in alcoholic solution :

$$
\mathrm{CH}_{3} \cdot \mathrm{CO} \cdot \mathrm{CH}_{2} \mathrm{Cl}+\mathrm{CH}_{3} \cdot \mathrm{COOK}=\mathrm{CH}_{3} \cdot \mathrm{CO} \cdot \mathrm{CH}_{2} \cdot \mathrm{O} \cdot \mathrm{C}_{2} \mathrm{H}_{3} \mathrm{O}+\mathrm{KCl} \text {. }
$$

Latterly, Laubmann (Annalen, 243, 244-248) has shown that solutions of acetylcarbinol, when treated with phenylhydrazine, yield an oily hydrazine compound, which, when heated with excess of the reagent, is converted into acetolosazone,

$$
\mathrm{CH}_{3} \cdot \mathrm{C}\left(\mathrm{N}_{2} \mathrm{H} \cdot \mathrm{C}_{6} \mathrm{H}_{5}\right) \cdot \mathrm{CH}\left(\mathrm{N}_{2} \mathrm{H} \cdot \mathrm{C}_{6} \mathrm{H}_{5}\right) \text {. }
$$

The formation of this substance, which is identical with the phenylhydrazine compound of methylglyoxal, $\mathrm{CH}_{3} \cdot \mathrm{CO} \cdot \mathrm{COH}$ (v. Pechmann, Ber., 20, 2543), proved conclusively the presence of acetylcarbinol in these solutions.

The difficulty experienced in obtaining acetylcarbinol by the hydrolysis of any of its compounds is due, in the first place, to the readiness with which it undergoes change when treated with reagents; and, secondly, to its extreme solubility in water, which renders extraction with ether or other solvents almost impossible, even in the case of moderately strong solutions.

In the course of a long series of experiments on the isolation of acetylcarbinol, extending over a number of years, it occurred to me that if chloracetone was boiled with water and some substance, such as barium carbonate, which, while capable of exercising a hydrolytic action, would, on account of its insolubility in water, be incapable of further action on the acetylcarbinol formed, very strong solutions of acetylcarbinol might be prepared from which the alcohol could be isolated by extraction with ether, thus :-

$$
\begin{array}{r}
2 \mathrm{CH}_{3} \cdot \mathrm{CO} \cdot \mathrm{CH}_{2} \mathrm{Cl}+\mathrm{BaCO}_{3}+\mathrm{H}_{2} \mathrm{O}=2 \mathrm{CH}_{3} \cdot \mathrm{CO} \cdot \mathrm{CH}_{2} \cdot \mathrm{OH}+\mathrm{BaCl}_{2} \\
+\mathrm{CO}_{2} .
\end{array}
$$

This method was investigated by Dr. J. B. Tingle and myself, and small quantities of acetylcarbinol were actually obtained in this way; 
but the yield was so small, and the isolation of the product so tedious, that at that time no further experiments were made on the subject.

On resuming the investigation, it was discovered that the hydrolysis. of acetylcarbinyl acetate by means of water and barium carbonate took place much more readily than that of chloracetone, and, further, that dilute solutions of acetylcarbinol could be concentrated by distillation; taking advantage of these two facts, a method was devised by which large quantities of acetylcarbinol can be obtained in a comparatively short space of time.

This method, which is described in detail in this paper, is briefly as follows:- Acetylcarbingl acetate is boiled in aqueous solution with barium carbonate until completely hydrolysed, the resulting product freed from barium acetate by distillation under reduced pressure, and the strong aqueous solution of acetylcarbinol thus obtained separated from the bulk of the water by careful fractionation. In this way nearly the whole of the water may be removed, and the resulting 90 per cent. acetylcarbinol, after drying over anhydrous sodium sulphate, and distillation under reduced pressure, can be readily obtained pure.

Acetylcarbinol is a peculiarly smelling, colourless oil which boils at $147^{\circ}$, and solidifies at low temperatures; it is miscible in all proportions with water; it reduces ammoniacal solution of nitrate of silver and Fehling's solution in the cold; sodium amalgam converts it quantitatively into methyl glycol:-

$$
\mathrm{CH}_{3} \cdot \mathrm{CO} \cdot \mathrm{CH}_{2} \cdot \mathrm{OH}+\mathrm{H}_{2}=\mathrm{CH}_{3} \cdot \mathrm{CH}(\mathrm{OH}) \cdot \mathrm{CH}_{2} \cdot \mathrm{OH} \text {. }
$$

I hope at a future date to communicate to the Society the results of further experiments on this interesting substance.

\section{Acetylcarbinyl Acetate, $\mathrm{CH}_{3} \cdot \mathrm{CO} \cdot \mathrm{CH}_{2} \cdot \mathrm{O} \cdot \mathrm{C}_{2} \mathrm{H}_{3} \mathrm{O}$.}

This substance has already been prepared by Henry (Ber., 5, 966), and by Zincke and Breuer (Ber., 13,638); it is readily produced by digesting monochloracetone with potassium acetate in alcoholic solution :

$$
\mathrm{CH}_{3} \cdot \mathrm{COOK}+\mathrm{CH}_{3} \cdot \mathrm{CO} \cdot \mathrm{CH}_{2} \mathrm{Cl}=\mathrm{CH}_{3} \cdot \mathrm{CO} \cdot \mathrm{CH}_{2} \cdot \mathrm{O} \cdot \mathrm{C}_{2} \mathrm{H}_{3} \mathrm{O}+\mathrm{KCl} \text {. }
$$

In preparing large quantities of acetylcarbinyl acetate, the method employed was that recommended by Zincke and Breuer, but slightly modified, in order to produce as large a yield as possible.

200 grams of pure, dry potassium acetate was mixed with about twice its weight of absolute alcohol, 185 grams of monochloracetone added, and the mixture heated on a water-bath in a flask connected with a reflux apparatus for two hours. After standing for 12 hours, 
the product was separated from the precipitated potassium chloride by filtration on a filter-pump, the residue washed two or three times with small quantities of absolute alcohol, and the dark-coloured alcoholic liquors slowly distilled until the greater bulk of the alcohol had been removed; it was then rapidly distilled, under a pressure of $150 \mathrm{~mm}$., from a strong, round-bottomed flask, heated by means of an oil-bath, until no more oily drops passed over. This method is far preferable to that recommended by Zincke and Breuer, namely, mixing the residue with water after distilling off the alcohol, and extracting with ether, as the acetate is not only miscible with water and difficult to extract by ether, but it is also, to a considerable extent, decomposed by solution in water, and great loss, therefore, occurs.

The crude acetylcarbingl acetate, obtained by the above method, is readily purified by fractional distillation, first under reduced pressure, and then at the ordinary pressure.

Pure acetylcarbinyl acetate boils at $174-175^{\circ}$ under a pressure of $760 \mathrm{~mm}$., and at $137-138^{\circ}$ under a pressure of $230 \mathrm{~mm}$. Two specially purified preparations gave, on analysis, the following numbers:-

I. 0.1540 gram substance gave 0.0972 gram $\mathrm{H}_{2} \mathrm{O}$ and 0.2913 gram $\mathrm{CO}_{2}$.

II. 0.2402 gram substance gave 0.1473 gram $\mathrm{H}_{2} \mathrm{O}$ and 0.4538 gram $\mathrm{CO}_{2}$.

\begin{tabular}{|c|c|c|c|c|}
\hline & & & und. & \\
\hline & $\begin{array}{l}\text { Theory. } \\
\mathrm{C}_{5} \mathrm{H}_{8} \mathrm{O}_{3} \text {. }\end{array}$ & I & II & \\
\hline$\ldots \ldots \ldots$ & 51.72 per cent. & $51 \cdot 57$ & $51 \cdot 50$ & r cent. \\
\hline$H \ldots \ldots$. & $6.90 \quad$, & $7 \cdot 01$ & 6.81 & $"$ \\
\hline $0 \ldots \ldots$ & $41 \cdot 38$ & $41 \cdot 42$ & $41 \cdot 69$ & " \\
\hline
\end{tabular}

If the materials used in the above method of preparation are carefully dried, and precautions are taken to exclude moisture in the subsequent purification of the crude product, the yield obtained is about $80-85$ per cent. of the theoretical; and this yield may be still further improved by using the alcohol from one operation for a subsequent preparation, as the small quantities of the acetate which always distil over with the alcohol may in this way be recovered.

Acetylcarbinyl acetate is a colourless, limpid liquid possessing a peculiar, sickly odour; it is miscible with water, and to some extent decomposed by it; the aqueous solution, on standing, acquires a very acid reaction. The density and magnetic rotation of this substance were determined by W. H. Perkin, sen., with the following results :-

Density : $-d 4^{\circ} / 4^{\circ}=1.0912 ; d 10^{\circ} / 10^{\circ}=1.0849 ; d 15^{\circ} / 15^{\circ}=1.0803 ;$ $d 20^{\circ} / 20^{\circ}=1 \cdot 0760 ; d 25^{\circ} / 25^{\circ}=1.0719$. 
Magnetic Rotation.

\begin{tabular}{|c|c|c|c|}
\hline & $t$. & Sp. rotation. & Mol. rotation. \\
\hline & $\begin{array}{l}15 \cdot 2^{\circ} \\
13 \cdot 2 \\
13 \cdot 0 \\
13 \cdot 0 \\
13 \cdot 0 \\
13 \cdot 5 \\
13 \cdot 0 \\
13 \cdot 0\end{array}$ & $\begin{array}{l}0 \cdot 9091 \\
0.9150 \\
0.9091 \\
0.9076 \\
0.9091 \\
0.9091 \\
0.9137 \\
0.9113\end{array}$ & $\begin{array}{l}5 \cdot 424 \\
5 \cdot 458 \\
5 \cdot 418 \\
5 \cdot 409 \\
5 \cdot 418 \\
5 \cdot 416 \\
5 \cdot 440 \\
5 \cdot 426\end{array}$ \\
\hline Average .. & $13 \cdot 4$ & 0.91 .05 & $5 \cdot 426$ \\
\hline
\end{tabular}

The theoretical magnetic rotation of acetylcarbinyl acetate may be calculated thus :-

Acetylcarbinyl acetate results from the substitution of one of the hydrogen atoms in acetone by the group $\mathrm{CH}_{3} \cdot \mathrm{COO}$.

The value of this group replacing an atom of hydrogen may be deànced as follows :-

I. Magnetic rotation of octyl acetate ......... 10.601 Magnetic rotation of octane (cal.).......... 8.692

Difference $=$ Magnetic rotation of the group $\} 1.909$
$\mathrm{CH}_{3} \cdot \mathrm{COO}$, replacing hydrogen

II. Magnetic rotation of propyl acetate ........ $\overline{5 \cdot 487}$ Magnetic rotation of propane (cal.) ......... 3.577

$\left.\begin{array}{c}\text { Difference }=\text { Magnetic rotation of the group } \\ \mathrm{CH}_{3} \cdot \mathrm{COO} \text {, replacing hydrogen }\end{array}\right\} 1.910$

If now we add this value to the magnetic rotation of acetone $=3.514$, we obtain 5.424 as the theoretical magnetic rotation of acetylcarbingl acetate, a number which agrees very closely with that actually found, namely, $5 \cdot 426$.

\section{A cetylcarbinol, $\mathrm{CH}_{3} \cdot \mathrm{CO} \cdot \mathrm{CH}_{2} \cdot \mathrm{OH}$.}

In order to prepare acetylcarbinol from its acetate, numerous experiments were made with various hydrolysing agents under the most varied conditions, but it was soon discovered that most of these were worthless, on account of their decomposing action on the acetylcarbinol produced.

The best results were obtained with moist barium carbonate, and 
ultimately the following method, which I give in detail, was adopted as giving a very satisfactory yield of the ketone alcohol :-

160 grams of pure acetylcarbinyl acetate is dissolved in 300 c.c. of water, heated to boiling in a round-bottomed flask connected with a reflux apparatus, and pure, dry barium carbonate added, advantageously in the form of small pellets, in such a way that no further addition is made until the previous pellet has entirely dissolved. At the end of about three hours the reaction is complete, as is shown by the fact that the addition of a small quantity of barinm carbonate to the boiling liquid causes no further evolution of carbonic anhydride. The product is filtered from any trace of undissolved barium carbonate, and distilled as rapidly as possible, under a pressure of $100 \mathrm{~mm}$., from a round-bottomed flask, heated by means of a paraffin-bath, until no more liquid passes over, but care must be taken not to raise the temperature of the bath unnecessarily high, otherwise the residue in the flask, which still contains a considerable quantity of acetylcarbinol, and the treatment of which is described below, is apt to be decomposed.

The colourless distillate, which measures about 350 c.c., when tested with Fehling's solution, as described on p. 794, is found to contain about 15 per cent. of acetylcarbinol, or about $5 \mathrm{l}$ grams in all.

The residue in the distilling flask is dissolved in a little water and distilled in a rapid current of steam, the paraffin-bath being kept at about $120^{\circ}$.

The following table may serve as an example of the distillates collected, and the amount of acetylcarbinol contained in each as determined by titration :-

\begin{tabular}{|c|c|c|c|c|}
\hline & $\begin{array}{l}\text { Distillate } \\
\text { collucted. }\end{array}$ & $\begin{array}{l}\text { Fehling's solution } \\
\text { reduced by } 2 \text { c.c. }\end{array}$ & $\begin{array}{l}\text { Percentage of } \\
\text { acetylcarbinol. }\end{array}$ & $\begin{array}{l}\text { Total amount of } \\
\text { acetylcarbinol. }\end{array}$ \\
\hline $\begin{aligned} \text { II } & \ldots \\
\text { III } & \ldots \\
\text { IV } & \ldots \\
\text { V } & \ldots\end{aligned}$ & $\begin{array}{l}150 \text { c.c. } \\
104 \quad ", \\
100 \quad " \\
280 ", \\
210 ",\end{array}$ & $\begin{array}{l}38 \cdot 5 \text { c.c. } \\
25 \cdot 3 ", \\
19 \cdot 5 ", \\
11 \cdot 0, " \\
5 \cdot 5, "\end{array}$ & $\begin{array}{r}11 \cdot 5 \\
7 \cdot 6 \\
6 \cdot 0 \\
3 \cdot 3 \\
1 \cdot 7 \\
\quad \text { Total }\end{array}$ & $\begin{array}{c}17 \cdot 2 \text { grams. } \\
7 \cdot 9 \quad " \\
6 \cdot 0 \quad " \\
9 \cdot 2 \quad " \\
3 \cdot 5 \quad " \\
\frac{43 \cdot 8}{4} \text { grams. }\end{array}$ \\
\hline
\end{tabular}

The total amount of acetylcarbinol obtained from 160 grams of acetylcarbinyl acetate was therefore approximately 94 grams, whereas theoretically it should have been 103 grams; the hydrolysis by means of moist barium carbonate may therefore be considered as nearly quantitative.

In preparing large quantities of acetylcarbinol, the treatment of 
the aqueous solutions obtained as described above was approximately as follows :-

All the solutions containing from 6-7 per cent. of acetylcarbinol were first very slowly distilled from a large, round-bottomed flask fitted with a very long colonna, until the residue on titration was found to contain from 9 to 10 per cent. of the ketone alcohol. This resiaue was then mixed with other solutions of the same strength and the concentration continued until ultimately a residue was obtained which contains over 90 per cent. of acetylcarbinol.

In one series of experiments, in which 1 kilo. of pure acetylcarbinyl acetate was employed, the concentration of the aqueous solutions took about 14 days, and upwards of 450 grams of $90-95$ per cent. acetylcarbinol was obtained, together with large quantities of weak solntions. These weak solutions, when they contain less than 5 per cent. of acetylcarbinol, are best employed, instead of water, in decomposing fresh quantities of acetylcarbinyl acetate, as their concentration is not profitable.

In order to prepare pure acetylcarbinol, the $90-95$ per cent. product is dissolved in pure ether, the ethereal solution allowed to stand over anhydrous sodium sulphate for 24 hours, filtered, the ether slowly distilled off, and the residue fractioned under reduced pressure. Almost the whole passes over between $90^{\circ}$ and $105^{\circ}$, under a pressure of $150 \mathrm{~mm}$., at the first distillation, leaving, however, always a small residue in the retort, and on repeated fractionation pure acetylcarbinol is readily obtained boiling constantly at $96-97^{\circ}$ (150 mm.).

The following results were obtained on analysis:-

I. 0.1383 gram substance gave 0.1026 gram $\mathrm{H}_{2} \mathrm{O}$ and $0 \cdot 2460$ gram $\mathrm{CO}_{2}$

II. 0.2081 gram substance gave 0.1539 gram $\mathrm{H}_{2} \mathrm{O}$ and 0.3690 gram $\mathrm{CO}_{2}$.

III. $0 \cdot 1614$ gram substance gave $0 \cdot 1180$ gram $\mathrm{H}_{2} \mathrm{O}$ and $0 \cdot 2890$ gram $\mathrm{CO}_{2}$.

IV. 0.1890 gram substance gave $0 \cdot 1390$ gram $\mathrm{H}_{2} \mathrm{O}$ and $0 \cdot 3400$ gram $\mathrm{CO}_{2}$.

V. $0 \cdot 1700$ gram substance gave $0 \cdot 1244$ gram $\mathrm{H}_{2} \mathrm{O}$ and $0 \cdot 3050$ gram $\mathrm{CO}_{2}$.

\begin{tabular}{|c|c|c|c|c|c|c|}
\hline \multirow[b]{3}{*}{ C. } & \multirow{2}{*}{$\begin{array}{l}\text { Theory. } \\
\mathrm{C}_{3} \mathrm{H}_{6} \mathrm{O}_{2}\end{array}$} & \multicolumn{5}{|c|}{ Found. } \\
\hline & & I. & & III. & IV. & v. \\
\hline & 48.65 p. c. & $48 \cdot 51$ & $48 \cdot 36$ & $48 \cdot 83$ & $49 \cdot 05$ & $48 \cdot 93 \mathrm{p}$ \\
\hline & $8 \cdot 10^{\prime}$ & $8 \cdot 24$ & $8 \cdot 21$ & $8 \cdot 12$ & $8 \cdot 17$ & $8 \cdot 13$ \\
\hline & $43 \cdot 24$ & $43 \cdot 25$ & $43: 43$ & $43 \cdot 05$ & $42 \cdot 78$ & $42 \cdot 94$ \\
\hline
\end{tabular}

The vapour density of this substance, determined by Hofmann's method in toluene vapour, gave the following results :- 

Theory.
$\mathrm{C}_{3} \mathrm{H}_{6} \mathrm{O}_{2}$
D. .... $37 \cdot 0$
Found.

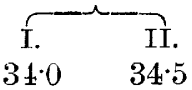

The molecular weight of acetylcarbinol was also determined by Raoult's method, using acetic acid as the solvent; the results obtained were the following :-

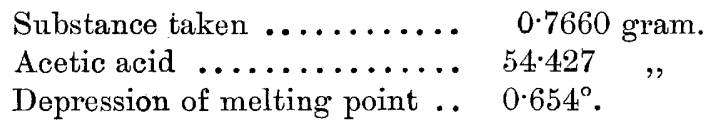

Molecular weight of substance found from the above data.. 85

Theory for $\mathrm{C}_{3} \mathrm{H}_{6} \mathrm{O}_{2} \ldots \ldots \ldots \ldots \ldots \ldots \ldots \ldots \ldots \ldots \ldots \ldots \ldots \ldots \ldots$

Acetylcarbinol is a colourless oil of a faint, sickly odonr closely resembling that of the acetate; it boils constantly at $105-106^{\circ}$ under a pressure of $200 \mathrm{~mm}$. with very slight decomposition, and at about $147^{\circ}$ under the ordinary pressure, but in the latter case not without decomposition, as a residue of high boiling point is always left in the retort. This residue, which probably contains condensation products of acetylcarbinol, on long standing, deposits crystals which have not yet been examined.

In a freezing mixture of powdered ice and hydrochloric acid, acetylcarbinol becomes quite thick, like glycerol, and on one occasion the substance solidified to a hard, crystalline mass.

It mixes with water, alcohol, and ether in all proportions, but is not precipitated from its aqueous solution by potassium carbonate, as is the case with solutions of acetopropyl alcohol and acetobutyl alcohol. The aqueous solution reduces ammoniacal silver solution and Fehling's solution in the cold; in the latter case the copper soluiion often remains unaltered for some seconds after mixing with the acetylcarbinol solution, particularly when this is weak, and then all at once reduction sets in. In some quantitative experiments it was found that 0.1 gram of acetylcarbinol dissolved in 50 c.c. of distilled water reduced about $16 \cdot 5-16 \cdot 6$ c.c. of Fehling's solution (1 c.c. contains 0.03464 gram $\mathrm{CuSO}_{4}, 5 \mathrm{Aq}=0.005$ gram grape sugar), but it is extremely difficult to accurately detect the end point of the reaction, as the solution becomes slightly yellowish during the reduction. According to Zincke (Ber., 13, 2344), lactic acid is formed during this decomposition, thus :-

$$
\mathrm{CH}_{3} \cdot \mathrm{CO} \cdot \mathrm{CH}_{2} \cdot \mathrm{OH}+\mathrm{O}=\mathrm{CH}_{3} \cdot \mathrm{CH}(\mathrm{OH}) \cdot \mathrm{COOH} ;
$$

and the amount of Fehling's solution reduced in the above experiments gives approximately 1 atom of oxygen to 1 mol. of acetylcarbinol. 
Fehling's solution may, therefore, be used as a valuable test of the strength of aqueous acetylcarbinol solutions, and for this purpose about 2 c.c. of a weak solution (to 10 per cent.), or 1 c.c. of a stronger solution, is diluted with 50 c.c. of water, heated to about $80^{\circ}$, and Fehling's solution run in, as in the estimation of sugar, using, however, a flask instead of a porcelain dish, to avoid evaporation; the strength of the solution may then be roughly calculated from the data given above.

The determination of the density and magnetic rotation of acetylcarbinol was undertaken by W. H. Perkin, senr, and the following are the results of his experiments.

Density $:-d 4^{\circ} / 4^{\circ}=1 \cdot 0904 ; d 15^{\circ} / 15^{\circ}=1 \cdot 07915 ; d 25^{\circ} / 25^{\circ}=1 \cdot 07069$.

\section{Magnetic Rotation.}

\begin{tabular}{|c|c|c|c|}
\hline & $t$ & Sp. rotation. & Mol. rotation. \\
\hline & $\begin{array}{c}15 \cdot 5^{\circ} \\
" \\
" \\
" \\
",\end{array}$ & $\begin{array}{l}0 \cdot 9571 \\
0 \cdot 9595 \\
0 \cdot 9550 \\
0 \cdot 9624 \\
0 \cdot 9543 \\
0 \cdot 9580\end{array}$ & $\begin{array}{l}3 \cdot 647 \\
3 \cdot 656 \\
3 \cdot 640 \\
3 \cdot 668 \\
3 \cdot 637 \\
3 \cdot 651\end{array}$ \\
\hline Average .. & $15 \cdot 5$ & 0.9577 & $3 \cdot 650$ \\
\hline
\end{tabular}

The magnetic rotation of acetylcarbinol may be calculated from that of methyl alcohol by adding the value of the acetyl group replacing hydrogen. This latter value may readily be obtained thus:-

Magnetic rotation of ethyl acetoacetate ........ 6.501

$" \quad, \quad$ ethyl acetate.............. 4.462

Difference $=$ Value of the acetyl group replacing
hydrogen 2.039

The magnetic rotation of methyl alcohol is $1 \cdot 640$, and this added to 2.039 gives 3.679 as the magnetic rotation of acetylcarbinol, a number which agrees well with that actually found, namely, $3 \cdot 650$.

\section{Preparation of Acetylcarbinol from Monochloracetone.}

The first sample of acetylcarbinol obtained was prepared by Dr. J. B. Tingle and myself (Proc., 73, 156) from monochloracetone by hydrolysis with water and precipitated barium carbonate; the following is an outline of the process adopted :- 
25 grams of monochloracetone is slowly added from a dropping funnel to 200 c.c. of water containing an excess of freshly-precipitated barium carbonate in suspension, the whole being vigorously boiled during the operation. As soon as the monochloracetone has dissolved, and the evolution of carbonic anhydride has practically ceased, the liquid is filtered, and the resulting, almost colourless solution distilled.

The distillate is again treated with chloracetone and barium carbonate, and again distilled, the operation being repeated until 150 grams of chloracetone has been decomposed. The resulting moderately concentrated solution of acetylcarbinol is saturated with potassium carbonate, and extracted at least 50 times with pure ether. The ethereal solution is thoroughly dried over ignited potassium carbonate, and is then slowly evaporated; a colourless oil remains, the greater part of which, on distillation, passes over between $140^{\circ}$ and $150^{\circ}$. On refractioning, a considerable quantity was obtained, boiling at $145-150^{\circ}$, which gave, on analysis, numbers agreeing with the formula $\mathrm{CH}_{3} \cdot \mathrm{CO} \cdot \mathrm{CH}_{2} \cdot \mathrm{OH}:-$

$0 \cdot 15+6$ gram substance gave $0 \cdot 1160$ gram $\mathrm{H}_{2} \mathrm{O}$ and 0.2766 gram $\mathrm{CO}_{2}$.

\begin{tabular}{|c|c|c|c|c|}
\hline .. & $\begin{array}{r}T \\
\mathrm{C} \\
48 \cdot 65\end{array}$ & $\begin{array}{l}y . \\
{ }_{2} \cdot \\
\text { cent. }\end{array}$ & $48 \cdot 73^{\mathrm{E}}$ & $\begin{array}{l}\text { d. } \\
\text { cent. }\end{array}$ \\
\hline. & $8 \cdot 10$ & , & $8: 33$ & , \\
\hline . & $43 \cdot 24$ & ", & $42 \cdot 94$ & , \\
\hline
\end{tabular}

The vapour density of this product was determined by Hofmann's. method in xylene vapour, with the following results:-

$$
\begin{aligned}
& \overbrace{\text { II }}^{\text {Found. }} \\
& \text { D......... } 37 \quad 35 \quad 34
\end{aligned}
$$

The amount of acetylcarbinol obtained by this method was very small, but the yield could no doubt be much improved by concentrating the aqueous solution and isolating the ketone alcohol in the manner described on p. 792.

\section{Action of Phenylhydrazine on Acetylcarbinol. \\ Acetylearbinol Osazone, $\mathrm{CH}_{3} \cdot \mathrm{C}\left(\mathrm{N}_{2} \mathrm{H} \cdot \mathrm{C}_{6} \mathrm{H}_{5}\right) \cdot \mathrm{CH}\left(\mathrm{N}_{2} \mathrm{H} \cdot \mathrm{C}_{6} \mathrm{H}_{5}\right)$.}

The phenylhydrazine compound of methylglyoxal (acetylcarbinol osazone) was first prepared by v. Pechmann (Ber., 20, 2543), by warming together aqueous solutions of methylglyoxal (or nitrosoacetone) and phenylhydrazine, thus :- 
$\mathrm{CH}_{3} \cdot \mathrm{CO} \cdot \mathrm{COH}+2 \mathrm{~N}_{2} \mathrm{H}_{3} \cdot \mathrm{C}_{6} \mathrm{H}_{5}=\mathrm{CH}_{3} \cdot \mathrm{C}\left(\mathrm{N}_{2} \mathrm{H} \cdot \mathrm{C}_{6} \mathrm{H}_{5}\right) \cdot \mathrm{CH}\left(\mathrm{N}_{2} \mathrm{H} \cdot \mathrm{C}_{6} \mathrm{H}_{5}\right)$ $+2 \mathrm{H}_{2} \mathrm{O}$.

Subsequently, H. Laubmann (Annalen, 243, 244-248) obtained the same substance by treating a solution of acetylcarbinol with phenylhydrazine. In order to prove that the substance described as acetylcarbinol in this paper really has this constitution, 5 grams of the pare substance was dissolved in 50 grams of water, a strong solution of phenylhydrazine added in excess, and the oily phenylhydrazine compound which separated digested in a sealed tabe with excess of phenylhydrazine at $100-105^{\circ}$.

The crude osazone thus obtained, after recrystallisation from dilute alcohol, gave the following numbers on analysis :-

$0 \cdot 1790$ gram substance gave $33 \cdot 8$ c.c. nitrogen; $t=16^{\circ} ;$ bar. $=$ $761 \mathrm{~mm}$.

$$
\begin{aligned}
& \text { Theory. } \\
& \mathrm{C}_{15} \mathrm{H}_{16} \mathrm{~N}_{4} \text {. Found. } \\
& \text { N . . . . 22.22 per cent. } 22 \cdot 20 \text { per cent. }
\end{aligned}
$$

This substance melted at $145^{\circ}$, and was identical in its properties with the compound described by v. Pechmann and H. Laubmann (loc. cit.).

Reduction of Acetylearbinol.

Formation of Methylglycol, $\mathrm{CH}_{3} \cdot \mathrm{CH}(\mathrm{OH}) \cdot \mathrm{CH}_{2} \cdot \mathrm{OH}$.

Acetylcarbinol is readily reduced by sodium amalgam with formation of methylglycol, thus :-

$$
\mathrm{CH}_{3} \cdot \mathrm{CO} \cdot \mathrm{CH}_{2} \cdot \mathrm{OH}+\mathrm{H}_{2}=\mathrm{CH}_{3} \cdot \mathrm{CH}(\mathrm{OH}) \cdot \mathrm{CH}_{2} \cdot \mathrm{OH} \text {. }
$$

In carrying out this experiment, a quantity of a 10 per cent. solution of acetylcarbinol was transferred to a flat porcelain dish, and treated with twice the calculated quantity of $2 \frac{1}{2}$ per cent. sodium amalgam, in small portions at a time. As soon as the reduction was complete, the product was separated from the mercury, neutralised with hydrochloric acid, and slowly distilled from a flask, furnished with a long colonna, and heated by a paraffin-bath, until the residue deposited a quantity of crystals of salt. This residue was next mixed with absolute alcohol, an equal bulk of ether added, and after standing for 24 hours the solution of the glycol was separated from the precipitated salt by filtration, and evaporated; the crude oily product was then purified, first by distillation in a vacuum, and then at the ordinary pressure. In this way an almost theoretical yield of methylglycol was obtained, which boiled constantly at $188^{\circ}$. 
W. H. PERKIN, JUN. : ACETYLCARBINOL.

The analysis gave the following results :-

0.1798 gram substance gave 0.1696 gram $\mathrm{H}_{2} \mathrm{O}$ and 0.3132 gram $\mathrm{CO}_{2}$.

\begin{tabular}{|c|c|c|c|c|}
\hline & $\begin{array}{r}\text { Th } \\
\mathbf{C}_{3} \\
47 \cdot 37\end{array}$ & 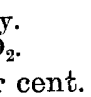 & $\begin{array}{r}\mathrm{F} \\
47 \cdot 50\end{array}$ & $\begin{array}{l}\text { d. } \\
\text { cent. }\end{array}$ \\
\hline$\cdots$ & 10.53 & $"$ & $10 \cdot 49$ & , \\
\hline . & $42 \cdot 10$ & , & $42 \cdot 01$ & , \\
\hline
\end{tabular}

Methylglycol was first obtained by Würtz (Ann. Chim. Phys. [3], 55,438 ) from propylene bromide, by digesting it with silver acetate, and subsequent hydrolysis of the acetate formed; Hartmann $(J . p r$. Ohem. [2], 16, 383) obtained the same substance in small quantity by boiling propylene bromide with an aqueous solution of sodium carbonate.

The boiling point and other properties of the substance obtained from acetylcarbinol are identical with those ascribed by Würtz to methylglycol.

The density and magnetic rotations of methylglycol were determined by W. H. Perkin, sen.

Density $:-d 4^{\circ} / 4^{\circ}=1 \cdot 0464 ; d 15^{\circ} / 15^{\circ}=1 \cdot 0389 ; d 25^{\circ} / 25^{\circ}=1 \cdot 03367$.

Magnetic Rotation.

\begin{tabular}{|c|c|c|c|}
\hline & $t$ & Sp. rotation. & Mol. rotation. \\
\hline & $\begin{array}{c}15 \cdot 5^{\circ} \\
", \\
", \\
,\end{array}$ & $\begin{array}{l}1 \cdot 0058 \\
1 \cdot 0061 \\
1 \cdot 0055 \\
1 \cdot 0018 \\
1 \cdot 0042\end{array}$ & $\begin{array}{l}4 \cdot 098 \\
4 \cdot 099 \\
4 \cdot 096 \\
4 \cdot 082 \\
4 \cdot 091\end{array}$ \\
\hline Average. & $15 \cdot 5$ & $1 \cdot 0047$ & $4 \cdot 093$ \\
\hline
\end{tabular}

